\title{
Climate Change and Ocean Acidification: Are We Just Treating the Symptoms?
}

\author{
David Finlay: david@theethicaldairy.co.uk \\ ( the paper is a non-peer reviewed preprint submitted to EarthArXiv.)
}

\section{Background}

The evidence that we are heading for irreversible, human caused climate change and ocean acidification with potentially catastrophic outcomes is now overwhelming. Despite all the rhetoric about addressing the causes of these crises, globally to date little has been achieved. Perhaps this is now about to change.

In the run-up to the COP 26 global climate summit in Glasgow, November 2021, governments and corporations across the world were rushing to demonstrate that they have a road map to, so called, 'net zero'. Net zero is where greenhouse gas emissions from somewhere are balanced by carbon that is locked up/sequestered in some way, often elsewhere. A popular method of achieving net zero is to buy carbon credits from those who are certified sequesterers of carbon through trading platforms like the UK and EU's emissions trading schemes (ETS). That the price of these carbon credits has shot up from the teens of euros where it had languished for many years to around 80 euros per tonne in recent months is an indication that things are moving.

All this activity centres around the strategy (Kyoto $1997^{1}$ ) of bringing climate change under control through reducing our net emissions of greenhouse gases to zero by 2050. This, it is argued, will also help us address ocean acidification. But there's a potential problem.

Now that governments, corporations and most individuals have got their heads around the idea of cutting net carbon emissions, it seems that a kind of 'group think' mentality ${ }^{2}$ has set in. The sheer momentum that has built around the evidence of the hundreds of scientists working in their respective climate fields has allowed us to ignore a growing science indicating that this strategy to address the threat of climate change and ocean acidification may be fundamentally flawed.

This paper does not in any way question the veracity of the research of these scientists. It does bring into question the logic behind the direction of travel at a strategic level, when viewed from the perspective of more recent works.

\section{A Quick Recap}

Solar energy in the form of short wavelength heat reaches the earth and is then dissipated by various processes ${ }^{3}$ - by plants using it to produce food, by convection, by evaporation, by reflection or by heat radiated back from the earth and into the atmosphere. The incoming short wavelength solar heat largely by-passes the greenhouse gases in the atmosphere, but the outgoing heat radiated from the warmed earth is long wavelength and it is this form of heat that becomes trapped by the atmospheric greenhouse gasses 
On the whole, this is a good thing as this insulating blanket of greenhouse gases keeps the temperature of the planet warm enough for us to thrive. Historically, natural processes have kept the planetary temperatures within habitable boundaries. However, in recent times our activities have increasingly disrupted those processes resulting in climate change from global warming. Additionally, the increases in atmospheric carbon dioxide from the burning of fossil fuels has been associated with ocean acidification ${ }^{4}$ and a resulting collapse in marine wildlife.

\section{The Greenhouse Gases}

By now, pretty well every school child knows the main greenhouse gases. Even most adults are aware that carbon dioxide and methane are the important greenhouse gases. A few have heard of nitrous oxide and hydrofluorocarbons and, possibly, even ozone. Few know that water vapour is also a greenhouse gas ${ }^{5}$.

The importance of these gases that act as a thermal blanket locking in the heat emanating from the earth depends on how effective a greenhouse gas they are and how frequently they occur in the atmosphere. Particularly in the first $12 \mathrm{~km}$ ( 8 miles, the troposphere), or so.

Okay, so let's look at the amount of energy the main greenhouse gases can trap. The energy in its longwave form is spread across a fairly wide spectrum. None of the greenhouse gases traps this heat across the entire spectrum. Some act over a fairly short range or ranges and some have quite a wide range of activity. Their range of activity depends on the physical characteristics of each gas's molecules.
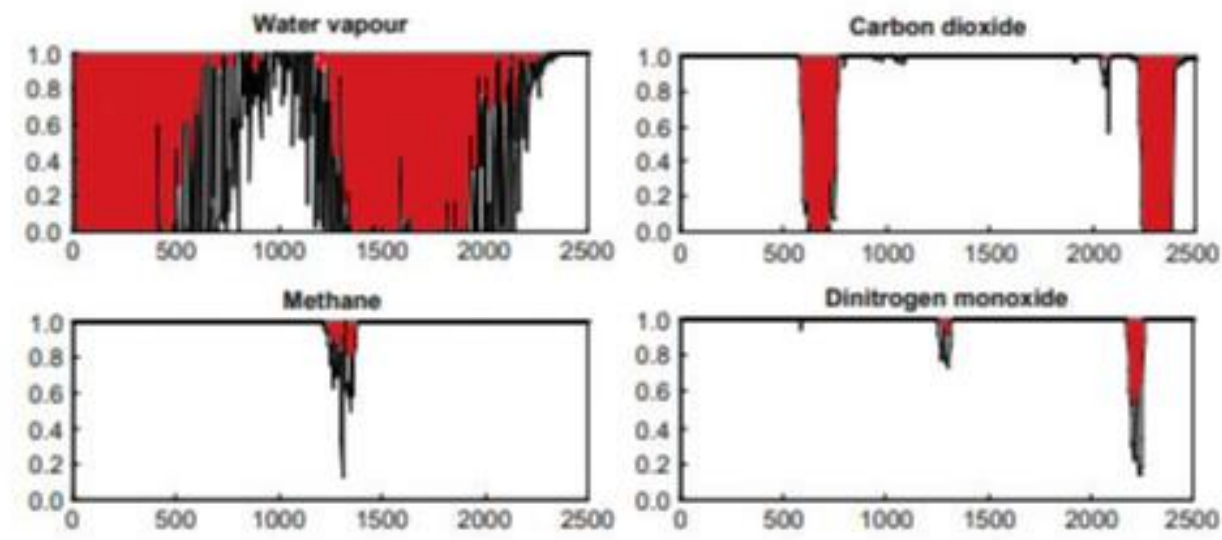

Figure 6: Infrared spectra of the greenhouse gases as calculated using the HITRAN data base'; Transmission is plotted against wavenumber (reciprocal $\mathrm{cm}$ )

As you can see from the graphs above ${ }^{6}$, water vapour has a very wide range of blocking activity (I've highlighted that in red), far greater than carbon dioxide, methane and nitrous oxide. Not only that, but there is a significant degree of overlap of water vapour activity with that of both carbon dioxide and methane. The significance of this is that any benefit from a reduction in these latter greenhouse gases is significantly buffered by the continued presence of water vapour in the atmosphere and over 
which we have no control. This, of course, is only half the story. The other important factor is, how frequently does each gas occur in the atmosphere.

Consider the make-up of the lower atmosphere, or troposphere. On average over $97 \%$ of the gases are not greenhouse gases. They are nitrogen and oxygen. If we take a million of these air molecules in the troposphere, on average about $\mathbf{4 1 2}$ are carbon dioxide ${ }^{7}$. Carbon Dioxide is the basic greenhouse gas against which all the other greenhouse gasses are measured. Just $\mathbf{2}$ will be methane ${ }^{7}$. You' $\mathbf{d}$ need to collect 3 million air molecules before you might find a nitrous oxide molecule ${ }^{7}$. However, in one million air molecules, on average there will be $\mathbf{2 5 , 0 0 0}$ water vapour molecules ${ }^{8}$.

This clearly means water vapour is overwhelmingly the most powerful part of the greenhouse gas 'thermal blanket surrounding the earth. The reason it is not considered to be a part of the global warming problem is due to the belief that the primary driver of climate change is the human produced increases we have seen in the other greenhouse gases in recent times. Undoubtedly that is a factor.

How much an additional greenhouse gas might add to the 'thermal blanket' is measured by its global warming potential (GWP) relative to carbon dioxide (CO2). GWP is calculated by combining the effectiveness of the gas molecule at blocking the heat coming off the earth with the amount of time that added molecule might stay around in the atmosphere. Any additional water vapour we add to the atmosphere only remains there for a few days compared to decades or centuries for the other greenhouse gases. From this perspective adding water vapour to the atmosphere is going to have little overall effect on the 'thermal blanket'.

This line of reasoning assumes that the primary driver of global warming comes from the additional greenhouse gases in the atmosphere and that there is no significant change in the amount of heat coming off the earth and into that thermal blanket.

Data collected and published in recent years clearly shows that this is a false assumption?

\section{The Real Drivers of Climate Change and Ocean Acidification}

Work published in $2018^{9}$, studying satellite data of the real-time impact of human caused land use change over the period 2000-2015, found that each stage of ecological degradation from primary forest right through to semi-arid scrub resulted in a substantial reduction in the global cooling effect of evapotranspiration and a corresponding increase in the global heating effect of long-wavelength terrestrial heat radiation.

The numbers are substantial. By the end of the 15-year study period alone the annual decrease in evaporative cooling from land use change amounted to 60 exajoules ( 60 followed by 18 zeros) and the annual increase in terrestrial, long-wavelength heat radiated into the atmosphere was 54 exajoules.

Extrapolating these numbers across the human-caused land use changes of past millennia (facilitated in recent times by the use of fossil fuels) shows a characteristic hockey-stick growth pattern of loss of transpiration cooling and gain of long-wavelength heat radiation. Indeed, the maths ${ }^{10}$ would indicate 
that ecological degradation has been a major driver of global warming all along. This fits with the contentious hypothesis of Professor WF Ruddiman back in $2005^{10}$ that human caused ecological disruption has been driving climate change for around 5,000 years.

This brings us to ocean acidification. The so-called 'evil twin' of global warming. Work published in 2021 by the Roslin Institute ${ }^{12}$ has identified the primary cause of the alarming $50 \%$ decline over the last 70 years in a keystone ocean species. Plankton.

Ocean acidification has been associated with the rise of carbon dioxide in the atmosphere ${ }^{13}$ which is in balance with carbon dioxide in the oceans. Carbon dioxide forms carbonic acid in water and it is this rise in carbonic acid concentration that is responsible for the acidification. However in a healthy ocean ecosystem, the plankton utilise the carbon dioxide in the water to produce food through photosynthesis, thus buffering the acidification potential. The $50 \%$ reduction in plankton numbers has severely compromised this buffering ability. The cause of this decline? The researchers have discovered that micro-plastics in the oceans are concentrating chemical pollutants on their surfaces and these in turn are being ingested or absorbed by the plankton causing death or reproductive failure. As plankton form the basis of ocean food webs, the researchers predict catastrophic collapse of the ocean ecosystem in around 25 years unless the release of these polluting plastics and vast range of, largely, untested chemicals is severely curtailed within the next 5-10 years.

\section{Discussion}

'Let's be clear... if we only pursue carbon mitigation strategies and don't do more to regenerate plant and animal life in oceans, we will reach a tipping point: a planetary boundary... and in 25 years when the [ocean] pH has dropped to $\mathrm{pH} 7.95$ represents the end point, the point of no return.' Words of the Roslin Innovation Centre's highly experienced GOES Team in their 2021 'think piece'.

Human caused ecological degradation is likely the primary driver of ocean acidification. True, the increase in atmospheric carbon dioxide is playing a part but the loss of $50 \%$ of the ocean's natural buffering capacity through pollution is an overwhelming factor. Eighty percent of global water waste passes into the oceans untreated. Few treatment plants remove chemical pollution. Even in the UK less than $10 \%$ of treatment plants remove chemical pollution. At the bottom of the Mariana trench the levels of PCB are 50 times greater than in the most polluted Chinese rivers.

From recent terrestrial research it would seem that human caused ecological degradation is also the likely primary driver of global warming ${ }^{14}$. The strategy to address global warming through reducing greenhouse gas emissions alone appears fundamentally flawed. With water in all its forms overwhelmingly influencing global thermodynamics ${ }^{14}$ and over which we have no control, trying to stop climate change through a greenhouse gas emissions strategy alone is like trying to change the course of a super-tanker using only a paddle.

It may not sound like it, but in fact this could be good news. We may still have a short window of opportunity to bring global warming and ocean acidification under some sort of control. Our efforts to reduce our greenhouse gas emissions, to date, have been a miserable failure and, with 
what some see as the 'smoke-and-mirrors' emissions accounting methodologies ${ }^{15}$, the prospects for any kind of success are both remote and, in any case, ultimately futile. The increase in human caused greenhouse gases in the atmosphere is more likely a symptom of ecological degradation than it is a primary driver of climate change and ocean acidification.

Controlling global warming and ocean acidification through regenerative practices is something we can all wholeheartedly support and, indeed, participate in. Ban the use of known chemical pollutants (polluter pays), stop the dumping of plastic into the environment, halt deforestation, stop cereal/soya-based intensive livestock farming, re-build forests/woodlands, plant cover crops on arable land, encourage agroecological and agroforestry farming systems, green urban areas and so on. It halts and reverses global warming and ocean acidification, re-builds land and ocean biodiversity, creates meaningful jobs, reduces pollution and antibiotic resistance and, most importantly, is real, nature-based (thus intrinsically safer than unproven technofix solutions) and is achievable.

\section{References}

1. https://www.pnas.org/content/98/9/4850

2. https://www.psychologytoday.com/gb/basics/groupthink

3. https://www.researchgate.net/figure/Schematic-representation-of-the-Earth-energybalance fig1 27775705

4. https://www.noaa.gov/education/resource-collections/ocean-coasts/ocean-acidification

5. https://energyeducation.ca/ wiki/index.php?title=Water vapour\&oldid=5216

6. http://warwickhughes.com/papers/barrett ee05.pdf

7. https://gml.noaa.gov/aggi

8. https://energyeducation.ca/ wiki/index.php?title=Water vapour\&oldid=5216

9. https://www.nature.com/articles/s41467-017-02810-8\#Sec2

10. https://doi.org/10.31223/X5PD2H

11. https://physics.ucf.edu/ britt/Climate/Reading5Did\%20humans\%20alter\%20global\%20climate.pdf

12. https://www.goesfoundation.com/media/1978/goesreportfeb21.pdf

13. https://www.noaa.gov/education/resource-collections/ocean-coasts/ocean-acidification

14. https://doi.org/10.31223/X5PD2H

15. https://environmentagency.blog.gov.uk/2021/05/10/carbon-offsetting-reviewing-theevidence/ 
